\title{
Configuração institucional e gestão do Sistema Único de Saúde: problemas e desafios*
}

\author{
Institutional configuration and administration \\ of Brazil's National Health System (SUS): problems and challenges
}

Jairnilson Silva Paim ${ }^{1}$

Carmen Fontes Teixeira ${ }^{1}$

\footnotetext{
*Texto elaborado para a Comissão de Políticas, Planejamento e Gestão em Saúdeda ABRASCO, como subsídio aos debates da 13 Conferência Nacional de Saúde, outubro de 2007. I nstituto deSaúde Coletiva, Universidade Federal da Bahia.
}

Abstract This paper analyzes the 'institutionality' of Brazil's National Health System, stressing crucial aspects to be dealt with, due to a return to the Public Health Reform Project. The reflection focus on the System's institutional configuration, covering issues related to the process for its political and management conduct, rooted in the authoritarian/patrimonialistic organizational culture of the Brazilian State, entangled in red tapeand colonized by private interests. It describes matters such as strategic resources/services management, hobbled by legal constraints imposed through economic policies, e.g. the Fiscal Liability Act; the inadequacy of subsidiary 'alternatives' suggested by managerialistic reforms cutting the System management processes; and the markedly amateur approach to administration due to the shortage of trained professionals and the ongoing clout of the old-boy network and pork-barrel politics when appointing civil servants to all level management positions. It presents arguments urging the introduction and consolidation of institutional innovations, similar to State Foundations created under private law, and discusses strategies to strengthen the governing capacities of the System's managing institutions, mainly the introduction of professional management with specific training and qualifications.

Key words Institutionality of Brazil's National $\mathrm{H}$ ealth System, $\mathrm{H}$ ealth management policy, $\mathrm{M}$ anagement alternatives
Resumo 0 trabalho analisa a problemática da "institucionalidade" do SUS, destacando alguns nós críticos a serem enfrentados para a retomada do projeto da Reforma Sanitária Brasileira. A reflexão diz respeito à configuração institucional do SUS, abarcando também aspectos relativos ao processo de condução político-gerencial do sistema, parte da cultura organizacional do Estado brasileiro, patrimonialista, autoritário, burocrático e colonizado por interesses privados. Descreve um conjunto de problemas, como o "engessamento" da gestão, por conta das limitações legais estabel ecidas em função da política econômica, a exemplo da Lei de Responsabilidade Fiscal, a inadequação das "alternativas" subsidiárias das reformas gerencialistas, que geram a fragmentação do processo de gestão, e o marcado amadorismo conseqüente à insuficiência de quadros profissionalizados, reprodução de práticas clientelistas e corporativas na indicação de ocupantes dos cargos de direção em todos os níveis. São apresentados argumentos favoráveis à introdução e consolidação de inovações institucionais, a exemplo das fundações estatais de direito privado e discute-se estratégias de fortalecimento da capacidade de governo das instituições gestoras do SU S, em particular a profissionalização da gestão e a formação profissional nesta área.

Palavras-chave Institucionalidade do SUS, Política de gestão da saúde, Alternativas de gestão 
0 processo da reforma sanitária brasileira é um projeto civilizatório, ou seja, pretende produzir mudanças dos valores prevalentes na sociedadebrasileira, tendo a saúde como eixo de transformação e a solidariedade como valor estruturante. 0 projeto do SU S éuma política de construção da democracia que visa a ampliação da esfera pública, a inclusão social ea redução das desigualdades. Todas as propostas devem ter como principal objetivo a melhoria das condições de saúde da população brasileira, a garantia dos direitos do cidadão, o respeito aos pacientes e a humanização da prestação de serviços ${ }^{1}$.

\section{Introdução}

O projeto da Reforma Sanitária Brasileira (RSB), ao postular a garantia do direito à saúde como componente da cidadania, indicava um conjunto de mudanças no Estado, na sociedade e na cultura, visando a melhoria da situação de saúde e das condições de vida da população. Como parte dessa totalidade de mudanças, defendia 0 princípio de que a saúde era um direito de todose um dever do Estado, propondo a instalação de um Sistema Ú nico de Saúde, democrático e descentralizado, com responsabilidades estabelecidas para as três esferas de governo.

Quando o tema central da 13a Conferência $\mathrm{N}$ acional de Saúde remete à expressão políticas de Estado, é justamente para ressaltar um compromisso e uma obrigação permanentes que não devem se submeter a interesses conjunturais de governos, partidos e corporações. Os governos responsáveis pela saúde no regime presidencialista brasileiro, embora concentrem-se no Executivo (federal, estadual emunicipal), devem interagir com o Legislativo eserem fiscalizados pelo Judiciário eM inistério Público. Deacordo com a legislação, essas diferentes esferas devem se relacionar de forma solidária (harmônica ou pactuada) para cumprir políticas nascidas da sociedade, como o SUS, articulando os diversos setores do Estado com o propósito de assegurar saúde e qualidade de vida para todos.

Enquanto processo, a Reforma Sanitária enfrentou-se com obstáculos consideráveis nos últimos vinte anos, apesar das conquistas indiscutíveis. Além da insuficiência einstabilidade do financiamento público para o SUS, persistem problemas de gestão, especialmente no que diz respeito aos estabelecimentos de saúde como hospitais eserviços de atenção básica. A falta de profissionalização de gestores, a descontinuidade administrativa, o clientelismo político ea interferência político-partidária no funcionamento dos serviços comprometem a reputação do SUS perante os cidadãos e a expectativa dos servidores públicos enquanto trabalhadores e partícipes de um projeto civilizatório do escopo da Reforma Sanitária Brasileira.

A reforma neoliberal iniciada na década passada, centrada num modelo gerencialista e na desresponsabilização do Estado para com parcela significativa dos direitos sociais conquistados, além de não resolver os problemas mencionados, criou outros com a disseminação de organizações sociais, OSCIPs, cooperativas e outras formas de terceirização da gestão e precarização do trabalho em saúde. A polarização entre a administração direta e a desresponsabilização estatal embotou a busca de alternativas que, respeitando os princípios e diretrizes da Reforma Sanitária e do SUS, fossem capazes de superar os problemas aludidos e assegurassem efetividade, qualidadeeeficiência nos serviços prestados pelo SUS.

Desse modo, cabe examinar impasses e perspectivas para um sistema de saúde que se pretende universal, integral, descentralizado e democrático, cujo processo de institucionalização não está descolado da natureza do Estado nem das características da sociedade brasileira. N esse sentido, 0 objetivo dessetrabal ho éidentificar eanalisar a problemática da "institucionalidade" do SUS, destacando alguns problemas que nos parecem "nós críticos" a serem desatados, tendo em vista a retomada e intensificação do projeto da Reforma Sanitária Brasileira.

\section{Uma nova "institucionalidade" para o SUS?}

Quando o SUS se encontra próximo de alcançar a sua maioridade, faz-se necessário reforçar certos propósitos que complementem e reforcem os princípios e diretrizes relativos à universalidade, integralidade, participação, descentralização e eqüidade. Assim, efetividade, resolutividade, legitimação, eficiência esustentabilidade constituem elementos centrais para o seu desenvolvimento. No caso da sustentabilidade, assenta-se em pelo menos cinco pilares: 1) econômico-financeiro; 2) jurídico-legal; 3) participação econtrole social; 4) constituição de sujeitos; 5) nova "institucionalidade".

Os três primeiros pilares têm sido contemplados de certa forma desde o início do SUS. A luta pela sustentabilidade econômico-financeira atravessou a infância e a adolescência do SU S e, 
presentemente, persiste na regulamentação da Emenda Constitucional 29 e, especialmente, na tramitação do PL 01/2003. No caso da sustentabilidadejurídico-legal, a inclusão do direito à saúde no texto constitucional e as leis orgânicas da saúde asseguraram as bases jurídicas para a sustentação do SUS. A participação e o controle social, junto ao movimento da RSB, evitaram retrocessos no arcabouço jurídico, envolvendo atualmente cerca de 150.000 consel heiros de saúde. A constituição de sujeitos individuais e coletivos comprometidos com o desenvolvimento do SUS e com o projeto da RSB tem ampliado, progressivamente, as bases sociopolíticas do movimento sanitário e tem permitido a reprodução de quadros solidários e de novas enti dades identificadas com a Reforma Sanitária.

Contudo, o recurso a tais pilares não tem sido suficiente para evitar retrocessos na gestão do SUS após experiências exitosas de governos munici pais eestaduais comprometidos com seus propósitos. São inúmeros os exemplos de descontinuidade administrativa, às vezes entre as forças de uma mesma coligação política ou entre correntes ou grupos de um mesmo partido. Casos como Santos, Campinas, Porto Alegre, Salvador, São Paulo, Bahia e Rio Grande do Sul, entre outros, apontam para a necessidade de construir formatos institucionais que reduzam a vulnerabilidade do SUS, assegurem certa proteção faceàs turbulências da vida político-partidária e possibilitem, simultaneamente, a efetividade, eficiência e eficácia da gestão.

0 termo "institucionalidade" refere-se, em primei ro lugar, à configuração institucional, isto é, ao desenho do SUS enquanto uma macro-organização, composta por um conjunto de instituições, situadas em várias esferas de governo federal, estadual emunicipal - que desempenham funções diversas, como financiamento, gestão, prestação de serviços, formação de recursos humanos e produção de insumos. Aponta para o elemento instituído de uma organização, determinada pelos propósitos de governo, método e pela História, conforme o postulado da coerência². E possibilita, sobretudo, pensar elementos instituintes capazes de revigorarem a "alma institucional", na medida em que problematizem o "motivo para que" e o "motivo por que" de uma instituição hipercomplexa ${ }^{3}$. A definição eredefinição deatribuições e competências de cada uma dessas instituições que compõem o SUS, a exemplo do MS, das SES e das SM S, bem, como das instituições a elas articuladas, como Agências (ANS, ANVISA) e Fundações (FUNASA, FIO-
CRUZ, etc.), em cada esfera de governo, constituem desafios no processo de reforma. Por outro lado, a "blindagem" do SUS mediante nova "institucionalidade" assegurando a profissionalização da gestão e carreiras específicas (gestor, saúde da família, administração hospitalar, etc.) requer um novo entejurídico da organização do Estado exclusivamente voltado para o SUS, com lógicas flexíveis, descentralizadas e ágeis de gestão que poderiam ser representadas pela seguinte construção: preservação de princípios, autonomia de meios e pactuação de fins.

Assim, a problemática da "institucionalidade" do SU Sabarca um conjunto de aspectos relativos ao processo de condução político-gerencial, isto é, à prática de gestão do sistema, processo complexo que, se por um lado pretende adotar como referencial os princípios incorporadosà legislação do SUS, quais sejam, descentralização com comando único em cada esfera de governo e participação social no processo decisório, por outro reproduz práticas políticas arraigadas na cultura organizacional do Estado brasileiro, notadamente na área social. Não cabe, portanto, confundir público com estatal, especialmente quando um Estado, como o brasileiro, é patrimonialista, autoritário, burocrático e colonizado por interesses privados, melhor dizendo, um "Estado burocrático enxertado de patrimonialismo" 4 .

Enfrentar o desafio de construir uma "nova institucionalidade" para o SUS significa, portanto, debruçar-se sobre os problemas e desafios que emanam da atual configuração macro-organizacional do sistema e do processo de gestão nos vários níveis do sistema, de modo a subsidiar a identificação de propostas al ternativas que contribuam para o fortalecimento e a consolidação de práticas coerentes com os princípios e valores da Reforma Sanitária. Daí a necessidade de ressaltar o caráter republicano do SUS e a Reforma Sanitária Brasileira como um projeto civilizatório.

Com isso, espera-se contribuir para o enfrentamento dos impasses gerados pelo Estado brasileiro para o pleno desenvolvimento do SUS, entre os quais se destacam: as reformas neoliberais; o clientelismo político; as políticas de ajuste macroeconômico; o monetarismo prevalecente nas políticas econômicas; e o desrespeito às disposições transitórias da Constituição eà Lei Orgânica da Saúde quanto ao financiamento a partir de decisões da chamada área econômica dos governos. Evidentementequenão sepretendeser exaustivo neste texto e sim demarcar uma posição favorável à introdução econsolidação deinovações institucionais e, principalmente, à incorporação 
de estratégias voltadas ao fortalecimento da capacidade de governo, isto é, da capacidade político-gerencial das instituições gestoras do SUS.

Institucionalização do SUS: problemas edesafios

0 processo de institucionalização da gestão do Sistema Ú nico de Saúde pode ser caracterizado como um movimento pendular de descentralização/centralização, regido pelo esforço deseimplantar o pacto federativo incorporado à Constituição de 1988. Esse processo, desencadeado fundamentalmente a partir de 1993, com o movimento em torno da "ousadia de cumprir a lei", tem sido pontuado, ao longo dosúltimos quinze anos, pela elaboração eimplementação de políticas e estratégias que incidem sobre a missão das instituições gestoras em cada esfera de governo, estabelecendo a configuração das relações intergovernamentais.

Esse movimento descentralizador foi iniciado com a implementação das N ormas O peracionais Básicas de 1993 (NOB 01/93) e especialmente a Norma Operacional Básica de 1996 (NOB 01/96) ${ }^{6}$, que induziram a redefinição de funções e competências das três esferas de governo (federal, estadual emunicipal) no que serefere à gestão, organização e prestação de serviços de saúde, através da transferência de recursos (financeiros, basicamente, mas também físicos, humanos e materiais) do nível federal e estadual para os municípios?.

0 processo de (re)centralização, com ênfase no fortalecimento do papel das Secretarias Estaduais deSaúde, foi desencadeado com a elaboração e implementação da N orma O peracional da Assistência à Saúde (2001/2002), instrumento de política que pretendia estimular a regionalização da assistência através da organização de sistemas microrregionais de saúde, capazes de garantir economia de escala na compra de insumosea integralidade da atenção, a partir da implementação de redes de serviços que articulassem os vários níveis de atenção.

Esse processo foi temporariamente interrompido com a mudança de governo em 2003, instalando-se um debate acerca da opção excessivamente "normativa" adotada durante a década de 90, o que culminou com a aprovação dos Pactos da Saúde, em 2006, novo instrumento de política quepretendeinstituir um processo denegociação permanente entregestores, no sentido de garantir a implementação de políticas e ações prioritárias.
Com isso, o M inistério da Saúde tenta substituir a estratégica adotada anteriormente, qual seja, a de induzir a tomada de decisões no âmbito estadual e municipal a partir de incentivos financeiros, por uma outra centrada no compromisso político entre os gestores, a ser construído no espaço das Comissões Intergestores Tripartite, ao nível nacional, e das Comissões Intergestores Bipartites, em cada estado, mediante a assinatura de "Termos de Compromisso" pactuados politicamente.

Esse movimento pode ser interpretado deváriosângulos. Do ponto de vista político mais geral, essa reorientação pode ser atribuída à existência de concepções distintas acerca da forma de exercício do poder nos atores que compõem as diversas forças políticas em cena no processo de construção do SUS, as quais se expressam nos discursos e nas decisões adotadas pelos dirigentes das instituições gestoras nos diversos níveis. A alternância de poder, ou seja, a mudança dos dirigentes que ocuparam cargos na "era FHC", para os que assumiram o comando do MS no governo Lula, explica, em parte, a crítica à opção "normativa" e a adoção de uma perspectiva política pretensamente mais democrática.

0 aspecto mais importante a ser considerado nos parece, entretanto, a existência de concepções distintas acerca da "I magem-O bjetivo" do SU Squanto à sua configuração institucional, podendo-se identificar a existência de grupos municipalistas mais "ortodoxos" e grupos que defendem um certo "federalismo" na reestruturação da distribuição depoder no processo deconstrução do sistema. Cabe registrar, ademais, a ocorrência de mudanças de concepções, quando se constata certa alteração da posição política que determinados atores ocupam na estrutura de poder do SUS, o que revela predominância de um "realismo político" articulado a interesses político-partidários, que se sobrepõem ao debate acerca das funções e competências de cada esfera para governo no âmbito do SUS.

O cenário político-institucional no qual se apresenta a problemática da organização e gestão do sistema, dos serviços e dos recursos do SUS é, assim, extremamente dinâmico, instável, não só por conta da natureza do processo de descentralização/centralização descrito brevemente acima, mas, sobretudo, pela mudança na correlação de forças que se configuram no âmbito das instituições e das instâncias col egiadas que agregam gestores do sistema, como é o caso das Comissões Intergestores e mesmo dos órgãos representativos dos gestores- CONASS, CONA- 
SEM S - no Conselho Nacional de Saúde e nos seus correlatos estaduais e municipais.

N esse cenário, até mesmo a identificação dos problemas relativos à configuração institucional e ao processo de Gestão do SUS não é fácil, uma vez que é auto-referente, variando segundo o ponto de vista dos vários atores em situação, melhor dizendo, depende do referencial teórico e dos interesses e projetos políticos envolvidos na análise feita por cada ator.

Assumindo como perspectiva a defesa dos princípios constitucionais e admitindo a possibilidade e mesmo a necessidade de se buscar soluções criativas aos problemas existentes, cabe destacar al guns nós críticos, relativos ao desenho (estrutura organizacional) e ao processo de gestão do SUS, quais sejam:

1) Falta de clareza einsuficiência de consenso em torno da "Imagem-O bjetivo" do SUS, principalmente no que respeita ao seu desenho macroorganizacional, permanecendo implícito no debate político da área, distintas imagens, recobertas pela retórica do "SUS que queremos";

2) Em decorrência disso, não se chega a estabelecer um consenso em torno da missão, isto é, das funções e competências das diversas esferas de governo, reproduzindo-se, entre os diversos âmbitos - federal, estadual e municipal - e também em cada esfera, a tensão e o conflito decompetências entreas diversas instituições, mediadas pela negociação, e agora, "pactuação", em torno deresponsabilidades e recursos, em que peseuma parcela destes já serem transferidos de forma automática, fundo a fundo;

3) Insuficiente coordenação interna na direção nacional do SUS, o que se reflete no debate em torno da necessidade de um "M inistério Ú nico da Saúde", quer pela fragmentação institucional que se verifica ao interior do M S (resultante da integração orgânica, porém não funcional das estruturas e culturas oriundas do antigo Inamps e de outros órgãos vinculados ao antigo MS, como a Funasa), cabendo agregar também a falta de articulação entre o M S e as agências executivas (AN SeANVISA), cujos dirigentes estaff por vezes não se identificam como parte do SUS;

4) Dificuldades na comunicação/informação entre os três níveis de governo do SUS, em parte decorrente da heterogeneidade existente em termos do desenvolvimento institucional das Secretarias Estaduais e Municipais de Saúde (reflexo da heterogeneidade estrutural do país e da herança do antigo sistema), mas também fruto da "contaminação" das relações intergovernamentais por interesses político-partidários;
5) Falta de gestão profissionalizada, ou seja, persistência de marcado "amadorismo" na gestão do sistema em todos os níveis, tanto pela escassez de quadros qual ificados ao exercício das múltiplas e complexas tarefas relacionadas com a condução, planejamento, programação, auditoria, controle e avaliação, regulação e gestão de recursos e serviços, quanto pelo fato da persistência de clientelismo político na indicação dos ocupantes dos cargos e funções de direção em todos os níveis do sistema;

6) Fragilidade institucional e ineficiência da gestão de sistemas, serviços e recursos, em parte pela insuficiência no processo de incorporação de tecnologias de gestão adequadas ao manejo de organizações complexas, seja na área de planejamento, orçamentação, avaliação, regulação, sistemas de informação, seja na área de gestão de serviços, como hospitais e outras unidades de saúde que demandam a utilização de tecnologias einstrumentos de gestão modernos e adequados às especificidades das organizações de saúde;

7) "Engessamento" do processo de gestão de serviços e recursos estratégicos, a exemplo de insumos e força de trabalho, por conta das limitações legais estabelecidas em função das opções de política econômica, a exemplo da Lei de Responsabilidade Fiscal que limita o gasto público nas diversas esferas de governo, dificultando a realização de concursos para admissão de pessoal, algo que incide drasticamente no sistema de saúde, sabidamente um setor de produção "trabalho intensivo";

8) Inadequação das "alternativas" adotadas para a superação das limitações apontadas no item anterior, subsidiárias das propostas de reformas gerencialistas, que geram a fragmentação do processo de gestão do sistema, com perda da capacidade do gestor - federal, estadual e municipal - em imprimir a direcionalidade pre tendida no processo de implementação das políticas e programas do SUS;

9) Dificuldade dearticulação intersetorial entre o sistema de saúde e as demais instituições gestoras de políticas e programas na área econômica esocial, em parte pela existência de culturas organizacionais diversas, que reproduzem concepções e práticas de gestão, planejamento, programação e avaliação diferentes, em parte pela insuficiência dos esforços de construção de um patamar de diálogo e cooperação entre setores de modo a potencializar os efeitos das ações e serviços de saúde nos vários níveis do SUS;

10) M odus operandi do controle social provocando as tensões e disputas nem sempre perti- 
nentes abrangendo as competências e a legiti midade entre as instâncias executivas do SUS e o aparato do controle social, o que demanda a ampliação do debate em torno da prática decontrole social no SUS hoje, especial mente a análise da "captura" dos espaços de participação e controle social por organizações fortemente corporativas, representativas de grupos populacionais específicos ou de segmentos de corporações de profissionais e trabalhadores de saúde.

\section{Uma nova configuração institucional para o SUS?}

A reforma neoliberal promovida na década de 90 utilizou parte da argumentação em defesa da "publicização" do Estado para torná-lo menos público. A busca de alternativas para uma nova "institucionalidade" do SUS passa pela necessidade de garantir o seu caráter público e não, necessariamente, pela sua subordinação à chamada "administração direta do Estado", protegendo-o da descontinuidade administrativa e de intercorrências derivadas de manobras da política partidária.

É dever do SU S cuidar da vida e da saúde das pessoas que não podem ser comprometidas pelos humores, crenças, ideologias e vaidades dos dirigentes de plantão. D aí a necessidade de protegêlo da descontinuidade administrativa e deintercorrências desastrosas da gestão, posto que estão em jogo a vida e a saúde das pessoas. Cabe destacar a pertinência de investigar edebater novos formatos institucionais que possibilitem ao SUS cumprir o seu dever e alcançar o devir concebido pela Reforma Sanitária Brasileira

Apesar de polêmico, estetema merece estudo, reflexão, crítica e proposições, pois as evidências acumuladas vêm comprovando que as forças internas do SUS, sociais e políticas, esgotaram sua capacidade de promover por si a ruptura com os procedimentos desvirtuados pelo atual paradigma das políticas de Estado ${ }^{6}$. Cabe reconhecer que a Reforma D emocrática do Estado, preconizada pela RSB e iniciada pelo SUS, foi comprometida pela derrota do parlamentarismo que possibilitaria uma burocracia estável e responsável (accountability) e pelo clientelismo e favoritismo políticos que comprometem a governança (capacidade de governo) sob o pretexto da "governabilidade".

Ao contrário do discurso da Reforma Neoliberal do Estado, publicizar o SUS sem privatizálo significa assegurar uma autonomia relativa frente ao Estado, aos governos e aos partidos políticos, a partir da concepção deEstado ampliado. Tal proposta não deve ser confundida com privatização ou desresponsabilização do Estado na garantia do direito à saúde, mas um esforço de submetêlo ao controle público e democrático mediante gestão compartilhada pela sociedade civil, trabalhadores da saúde e governo. Universidades federais, fundações públicas, institutos de pesquisa e agências de cultura têm experimentado arranjos organizacionais nessa direção e poderiam ser um ponto de partida para enfrentar essa discussão, como sugere um dos seus formuladores: 0 SUS precisa caminhar, em uma fórmula intermediária, que mantém o caráter público, mas precisamos criar uma autarquia especial do SU S [...] Um grande problema das organizações estatais é a gestão exclusiva através do governo euma autarquia especial pode não se tornar instrumento partidário9.

Um debate dessa natureza extrapola os limites das instâncias de gestão colegiada do SU S devendo envolver, necessariamente, os distintos atores políticos, governamentais enão governamentais, de modo a ressoar nos Conselhos de Saúde e nas Conferências de Saúde, no Congresso Nacional, nos espaços de comunicação social, na mídia, por interessar a toda a população. A $13^{a}$ Conferência Nacional de Saúde pode ser o espaço em que esse tema seja incorporado à Agenda da Reforma Sanitária, discutindo-se uma estratégia de ampliação e qualificação do debate, envolvendo especial istas na área e autoridades políticas, organizações internacionais e estudiosos do tema ao nível internacional.

0 desenvolvimento dos estudos e debates necessários ao processo de tomada de uma decisão dessa magnitude não deve, entretanto, inviabilizar a adoção de propostas alternativas, de médio epequeno al cance, quejá estão sendo discuti das e elaboradas em vários estados e municípios brasileiros, com vistas ao enfrentamento dos problemas listados no item anterior ${ }^{10}$.

N essa perspectiva, cabe considerar a proposta decriação deFundações Estatais de Direito Privado que podem vir a ser uma alternativa defensável contra a proliferação de privatizações, terceirizações, organizações sociais e outras formas de delegação de responsabilidade sobre a gestão de programas, serviços e recursos do SUS, que tendem a provocar sua fragmentação e desmonte. A tentativa deimplantação açodada deorganizações sociais, por exemplo, mostrou-se desastrosa em algumas situações ${ }^{11}$. Ainda assim, há quem defenda a sua revisão em função do caráter público do SUS no sentido de alterar certos dis- 
positivos da legislação original e de corrigir limitações e desvirtuamentos verificados. De acordo com essa perspectiva de análise, as fundações estatais provavelmenteexigirão, além de uma lei complementar, uma lei ordinária que especifique sua maior autonomia administrativa principalmente no plano orçamentário, não sendo, portanto, razoável esperar aprovação para breve ${ }^{12}$.

\section{O queéfundação estatal?}

Não obstantecertas diferenças de concepção e de ênfase entre a proposta do M inistério de Planejamento, Gestão e Orçamento e aquela apresentada para o debate pela Secretaria da Saúde do Estado da Bahia (SESAB), verifica-se um crescente consenso de quea Fundação Estatal representa uma inovação institucional com grandes vantagens para a operação do SU S em comparação aos formatos de autarquia, autarquia especial (universidades federais e agências), empresa e fundação públicas. 0 governo federal colocou um texto para consulta pública e debate com a seguinte definição:

A fundação estatal éforma jurídica queintegra a administração pública indireta, ao lado das autarquias, das fundações públicas de direito público (fundações autárquicas), dos consórcios públicos de direito público ou privado, das empresas públicas e das sociedades de economia mista. É regida pelo regi mejurídico do direito privado, ao lado das empresas públicas e sociedades de economia mista e dos consórcios de direito privado.

Goza de autonomia gerencial, orçamentária e financeira, tal como as empresas estatais.[...] 0 direito de propriedade, a finalidadeinstitucional e o sistema de governança são públicos, assim como nos órgãos de administração direta, nas autarquias e nas fundações públicas. 0 sistema de governança inclui a participação de representantes da sociedade civil para promover o maior alinhamento possível entre as atividades da entidade e as necessi dades eexpectativas dos ci dadãos. 0 bserva um regime administrativo mínimo, assim como as empresas estatais ${ }^{13}$.

Ainda assim, a Fundação Estatal não pode ser vista como uma panacéia, diante da natureza do Estado brasileiro e dos limites da reforma política proposta, nem visa resolver os grandes nós da Reforma Sanitária, mas deve ser considerada como uma das alternativas inovadoras para a gestão de organizações complexas, como é 0 caso dos hospitais da rede própria do SUS, que sob essa modalidade de gestão poderiam fazer frente aos problemas decorrentes das amarras à legislação que rege licitações para compra de material e insumos, bem como teriam maior liberdade de ação para contratação de força de trabal ho necessáriaà mel horia do funcionamento dos serviços.

A criação de Fundações Estatais também pode ser uma alternativa para a gestão de recursos estratégicos envolvidos em uma extensa rede de serviços, como é o caso da gestão de pessoal empregado em programas ou áreas específicas, a exemplo da proposta de criação da Fundação Estatal para a Saúde da Família14, elaborada pela equipe que dirige a Atenção Básica do SUS na Secretaria de Saúde do Estado da Bahia. Esta foi amplamente debatida na 7 ạ Conferência Estadual de Saúde da Bahia, sendo recomendada por quatro dos cinco grupos de discussão e aprovada na plenária final por $70 \%$ dos delegados. Portanto, a academia deve debruçar-se sobre o tema e analisá-lo da forma mais fundamentada possível, pois o movimento sanitário, conselheiros, del egados egestores precisam dispor dos elementos necessários para a escolha e decisão informadas sobre tal questão.

Como se pode perceber, 0 debate e a experimentação de alternativas pode se dar em duas dimensões da "institucionalidade" do SUS, ou seja, ao nível da macro-organização do SUS, problematizando-se a possibilidade de constituição de uma "autarquia" que proteja o SU S das influências conjunturais, político-partidárias, corporativas e outras, ao tempo em que se desenvolve, no curto prazo, um processo de experimentação de alternativas gerenciais em áreas críticas que permitam aos gestores, notadamente aos gestores estaduais e municipais, nos municípios de médio e grande porte, retomarem e/ou consolidarem o processo de condução do SUS em direção à I magem-O bjetivo definida na legislação constitucional einfraconstitucional.

Superar o clientelismo, o corporativismo e o amadorismo

Os avanços conquistados na descentralização e a engenharia política exercitada para garantir o comando único em cada esfera de governo, diante da especificidade da Federação brasileira, não devem obscurecer a vulnerabilidade do sistema às mudanças de governos, de gestores e de partidos.

0 debate em torno de mudanças na estrutura organizacional do sistema como um todo, com eventual redefinição das relações intergoverna- 
mentais, assim como a introdução de mudanças na estrutura organizacional do M inistério deSaúde, Secretarias Estaduais e M unicipais deSaúdeé, portanto, o ponto de partida para a adoção de medidas que resultem no fortalecimento da capacidade de governo das instituições gestoras do SUS em seu respectivo âmbito de atuação.

Além disso, pensamos ser necessário um investimento redobrado na formação e constituição desujeitos, lideranças, técnicos, gerentes, "quadros", enfim, dotados decapacidade técnica ecompromisso político com o processo de Reforma Sanitária e a defesa do SU S democrático, qualificados a atuarem em diversos espaços e níveis de gestão e de condução política do sistema.

Trata-se da chamada "profissionalização da gestão do SUS", que já vem sendo discutida há alguns anos, sem que tenham sido adotadas medidas concretas para a criação da carreira de "gestor do SUS", o que implicaria a valorização dos profissionais que se dedicam cotidianamente às atividades de caráter gerencial nas diversas esferas de gestão e nos diversos níveis organizacionais do sistema.

N essa perspectiva, énecessário que os órgãos responsáveis pela gestão do trabalho em saúde, seja no âmbito federal, estadual emunicipal, avancem com a elaboração de propostas concretas para o estabelecimento de plano de cargos, carreiras e salários específico para o âmbito político-gerencial, demodo a estimular a realização de concursos públicos que levem em conta a qualificação e a experiência dos profissionais no exercício dessas funções.

Algumas estimativas acerca do número de postos gerenciais no âmbito do SUS dão conta da necessi dade de formação e capacitação dealgo em torno de 100 a 120 mil profissionais, muito dos quais já vêm sendo formados e capacitados através de cursos de especialização em váriasáreas, oferecidos por universidades públicas e privadas, bem como, mais recentemente, através decursos de mestrado profissionalizante oferecidos por alguns programas de Pós-Graduação em Saúde Coletiva do país, a exemplo da EN PS/FIOCRUZ, UERJ eISC/UFBA.

Tais iniciativas contam com apoio institucional do M inistério da Saúde e de Secretarias Estaduais e Municipais de Saúde, constituindo um dos desdobramentos dos esforços que vêm sendo realizados nos últimos anos em torno da implementação de programas e atividades de formação e educação permanente dos profissionais e trabalhadores do SUS.

$\mathrm{Na}$ área gerencial, entretanto, a contraparti- da das instituições gestoras, em termos da valorização diferencial dos sujeitos formados por estes cursos, nem sempre se consolida, na medida em que prevalece a prática de distribuição decargos na estrutura administrativa em função dos interesses político-partidários ou pressões corporativas que obrigam os gestores a buscar garantir a "governabilidade" da sua gestão, reproduzindo-se, assim, o deplorável amadorismo que caracteriza a gestão do SU S em várias áreas.

0 enfrentamento e superação desses problemas passa, ao nosso ver, pelo fortalecimento de algumas iniciativas em curso, notadamente na área de planejamento e avaliação, desenvolvidas pelo MS, a exemplo do PlanejaSUS, bem como por iniciativas desencadeadas pelo CONASS e CONASEM S, a exemplo da implementação da Avaliação da Gestão Descentralizada do SUS (CON ASS) e a capacitação em larga escala de dirigentes e técnicos na área de gestão de sistemas e serviços, como é o caso da experiência desenvolvida no estado do Ceará. A expansão de cursos de graduação em gestão de saúde e a implantação da graduação em Saúde Coletiva ${ }^{15}$ seriam outros caminhos mais ousados.

Cabe destacar, inclusive, a necessidade de se qualificar o debate em torno das estratégias de educação permanente de profissionais e trabaIhadores do SUS, de modo a não apenas valorizar a incorporação de conhecimentos científicos e tecnologias de gestão no âmbito gerencial, senão que problematizar a dimensão ética dos processos de formação e capacitação de pessoal em todos os níveis, sem dúvida. Essa constituição de novos sujeitos sociais representa uma das "trincheiras" mais importantes no processo de retomada da luta pela Reforma Sanitária Brasileira.

Especificamente no âmbito da formação de dirigentes e técnicos qualificados a exercer funções de liderança na formulação e implementação de propostas político-gerenciais nos vários níveis deorganização egestão do SUS, éimportante ressaltar os compromissos com a qualidade e o reconhecimento da subjetividade, com a inovação e efetividade das ações, com a necessidade de valorização do esforço de "humanização" das relações interpessoais e com o desenvolvimento de práticas fundamentadas em valores como o respeito à diferença e a preservação e defesa da vida.

\section{Comentáriosfinais}

A Reforma Sanitária Brasileira enfatizava uma totalidade de mudanças passando pela Reforma 
Agrária, Reforma Urbana, Reforma Tributária, Reforma Universitária, ou ainda uma Reforma Intelectual e M oral como propunha o filósofo da práxis Antônio Gramsci. Embora inconclusa, a Reforma Sanitária não tem uma agenda esgotada. Pelo contrário, tem muito o que avançar no seu processo, considerando a radicalidade do seu projeto. A radicalização da democracia e a conquista da hegemonia política e cultural na sociedade civil pelos partidos socialistas e classes populares, com seus intelectuais orgânicos, poderão contribuir para a consolidação do SUS, sob controle público e, especialmente, para incidir no componente contraditório e revolucionário da reforma que é a saúde numa sociedade capitalis$\mathrm{ta}^{16}$. Conter $\mathrm{o}$ caráter patogênico do capital e redirecionar o Estado para regular o mercado, garantindo os direitos sociais conquistadosna Constituição de 1988, deveser um dos pressupostos de uma política conseqüente de desenvolvimento.

A pesar dea Reforma Sanitária propor a construção de um Sistema Ú nico de Saúde, o sistema de serviços de saúde ainda é fragmentado e subordinado a lógicas distintas: desde 0 interesse público ao objetivo de lucro e acumulação de capital, passando por espaços de realização de privilégio de corporações e de trocas clientelistas de partidos políticos. O SUS pode ser um grande exemplo de política pública democrática e descentralizada, mas os cidadãos têm pago uma alta taxa de maus tratos e de desumanização nas filas e nos serviços de saúde estatais e privados contratados. O fortalecimento do SUS passa pela garantia de um financiamento estável para o seu custeio e investimento na sua expansão que, no âmbito federal, deveria corresponder, no mínimo, a $30 \%$ do orçamento da seguridade social, segundo as disposições transitórias da Constituição de 1988. A aprovação do PL 01/2003 representa um passo necessário, embora insuficiente para a sustentação do SUS.

Não podehaver contingenciamento de recursos para a saúde enquanto a população é desassistida emorre pela fal ta ou precariedade do atendimento. Não deve haver complacência da Justiça diante de governantes que não cumprem a Constituição, sabotando os parcos recursos devidos para a saúde. A mídia, que tem sido tão diligentepara denunciar o "caos do SU S" eo "apagão da saúde", precisa contribuir no debate sobre as causas desses fenômenos e na identificação dos responsáveis.

O SUS é uma conquista e um patrimônio do povo brasileiro. E a população precisa tomar conhecimento das suas lutas, desua história para melhor compreender a ação dos seus algozes e pretensos coveiros, bem como os interesses espúrios que não ousam explicitar na esfera pública. Este éum dos paradoxos do SUS: seu sucesso como política pública pode significar um fracasso na atenção às pessoas, já que melhorias no financiamento, infra-estrutura, gestão e organização, apesar de fundamentais, não são suficientes para mudar 0 "modelo de desatenção" ${ }^{15}$ e assegurar o direito à saúde.

Portanto, o essencial do processo de construção do SUS implica a mudança do modelo de atenção á saúde, em busca de efetividade, qualidade e humanização das relações entre prestadores de serviços e usuários, como parte de um processo mais geral de mudança nas concepções acerca da saúde e no desenvolvimento das práticas de saúde. Além disso, o SUS, para ser efetivo, supõeuma Reforma Democrática do Estado para torná-lo realmente público. 0 controlesocial instaurado através de conferências e consel hos, assim como a gestão participativa dele resultante, não tem sido suficiente para superar as amarras burocráticas, aparentemente criadas para queele não venha a dar certo: U ma das práticas que mais favorece a corrupção no setor público é a distribuição de cargos sem base em critérios técnicos, visando apenas garantir "pedaços" da máquina pública a partidos políticos ou grupos constituídos, que transformam os cargos em balcões de negócios para troca de favores ou apoio em futuras campanhas políticas. Isso éainda muito mais gravequando acontece com servi ços públicos dos quais dependea vida e a saúde das pessoas. ${ }^{17}$

Daí a necessidade de experimentar novos formatos institucionais permeáveis à gestão compartilhada pela sociedade civil, trabal hadores da saúde e governo, com garantia de um corpo técnico estável através de seleção pública e carreiras específicas. A proposta de Fundações Estatais pode ser uma das alternativas. Os modelos de administração direta e de administração indireta (autarquias, fundações e empresas públicas) podem ser considerados, igualmente, estatais. Fora posições ideológicas, não há nada que indique qualidade e compromissos maiores para os órgãos da administração direta. Pelo contrário, usualmenteperdem em eficiência, eficácia e efetividade, além de serem maisfacilmente reféns das manobras da política partidária, do clientelismo, do fisiologismo e do favoritismo.

Entretanto, a aposta no modelo jurídico de Fundação Estatal não está livre das vicissitudes de um processo político democrático. Pode-se estabelecer as regras do jogo, mas não se garan- 
tem os resultados. $\mathrm{Na}$ dependência da correlação de forças, essa proposta pode apresentar-se mais conservadora ou progressista. Assim, a omissão, vacilação ou recuo das forças progressistas pode resultar no fortalecimento de projetos políticos neoliberais, conservadores, tecnocráticos e corporativos. M esmo admitindo-se a vitória das forças progressistas, a experiência do SUS indica que não basta a criação de uma lei para tornar uma situação irreversível. Antes da existência do SUS, jáhouveexperiência degestão pública mais flexível, como fundações e autarquias, a exemplo da Fundação de Saúde do Estado da Bahia (FUSEB) e Instituto de Saúde do Estado da Bahia (ISEB), responsáveis pela operação da rede de serviços da SESAB que sofreram, posteriormente, retrocessos e turbulências institucionais e depois extintas, enquadrando e engessando a gestão da saúde ao formato da administração direta, com sérias conseqüências para a descentralização, eficiência e eficácia da gestão ${ }^{18}$. Do mesmo modo, a tradição da superestrutura jurídico-política brasileira pode levar o judiciário a se colocar no sentido contrário à modernização pretendida na gestão pública da saúde, caso a proposta de fundação estatal não esteja bem fundamentada juridicamente, assentada em pareceres de constitucionalistas renomados, fortalecendo certa jurisprudência pertinente para seus propósitos virtuosos.

As fundações estatais, enfim, podem estabelecer contratos de gestão, especificando objetivos, metas, atividades erecursos, em vez de insistir no pagamento por procedimentos entre entes públicos. Pode instituir formas de trabalho não precarizadas, com carreiras específicas eingresso por concurso público. Têm a possibilidade de contribuir para a redução de cargos de confiança derivados de indicação político-partidária e de ampliar o controle social no cotidiano da gestão através de consel hos curadorese consultivos, sem prejuízo das atribuiç̧̃̃es dos conselhos de saúde respectivos. Finalmente, a indicação de dirigentes, em vez de se constituir em moeda de troca nos arranjos político-partidários sob o pretexto do alcance da "governabilidade", poderá passar, a partir de critérios de qualificação técnica, pelo crivo dos conselhos de saúde e/ou Parlamento, sendo nomeados pelo Executivo por um período de cinco ou seis anos.

Ao contrário do projeto de criação da Agência Federal de Prevenção e Controle de Doenças (APEC), medianteM edida Provisória (M P 33, 19/ 02/02) ${ }^{19}$ de acordo com o protótipo do CDC americano e com "proposições mais truculentas e retrógradas que as desenvolvidas pela polícia sanitária" 20 , sob a retórica da "publicização", flexibilização e melhora da remuneração de sanitaristas, a proposta das fundações estatais tem o potencial de fortalecer o movimento por uma Reforma Democrática de Estado centrada na cidadania, na liberdade e na sustentabilidade do SU S.

Portanto, os que defendem efetivamente 0 SUS e a Reforma Sanitária Brasileira precisam discutir alternativas de gestão que superem os obstáculos construídos pel os seus oponentes, seja pela burocracia estatal, seja pela área econômica, seja pela Lei de Responsabilidade Fiscal. Cabe à sociedadecivil exigir do Estado Brasileiro responsabilidade social e o dever com a saúde e a qualidade de vida dos cidadãos. $E$ às forças progressistas, em vez de caírem numa "estatolatria" sectária ou defenderem um Estado abstrato, cumpre compreender a natureza do Estado brasileiro realmente existente e acioná-lo como espaço de disputa de projetos e de luta de classes. E 0 SUS necessário que queremos precisa implodir este Estado de mal-estar que conhecemos: patrimonialista, privatizado, autoritário, burocrático eclientelista.

A "Reforma do Estado" empreendida na década de 90 para torná-lo "gerencial", regulador, fora da produção econômica e da prestação de serviços é distinta de uma Reforma Democrática do Estado para torná-lo efetivamente público. Esta passa pela radicalização da democracia e da Reforma Sanitária Brasileira, implantação da Seguridade Social e desenvolvimento do SUS, e pela formulação e condução de políticas contrahegemônicas. 


\section{Colaboradores}

\section{JS Paim e CF Teixeira participaram igualmente de todas as etapas da elaboração do artigo.}

\section{Referências}

1. Carta de Brasília. Documento final do 8o Simpósio sobre Política Nacional de Saúde. M edicina CFM 2005; 156:12-13.

2. Testa M. Pensar em saúde. Porto Alegre: Artes Médicas/ABRASCO; 1992.

3. Testa M. Análisis de instituciones hipercomplejas. In: M erhy EE, Onocko R, organizadores. Agir em saúde: um desafio para o público. São Paulo: Hucitec; Buenos Aires: Lugar Editorial; 1997. p.17-70.

4. Nogueira MA. As possibilidades da política. Idéias para a reforma democrática do Estado. Rio de Janeiro: Paz e Terra; 1998.

5. Brasil. M inistério da Saúde. Sistema Ú nico de Saúde. Descentralização das ações e serviços de saúde: a ousadia de cumprir e fazer cumprir a Lei. NOB 01/93. Brasília: Ministério da Saúde; 1993.

6. Brasil. Ministério da Saúde. Sistema Único de Saúde. Gestão plena com responsabilidade pela saúde do cidadão. NOB 01/96. Brasília: Ministério da Saúde; 1997.

7. Levcovitz E, Lima LD, Machado CV. Políticas de Saúde nos anos 90: relações intergovernamentais e o papel das Normas Operacionais Básicas. Rev C S Col 2001; 6(2):269-291.

8. ABRASCO, CEBES, ABRES, Rede Unida, AM PASA. $M$ anifesto: Reafirmando compromissos pela saúde dos brasileiros. Brasília: ABRASCO, CEBES, ABRES, Rede Unida, AM PASA; 2005.

9. Campos GWS. O público, o estatal, o privado e o particular nas políticas públicas de saúde. In: Heimann LS, Ibanhes LC, Barboza R. 0 público e o privado na saúde. São Paulo: Hucitec; 2005. p. 89-110.

10. Trevisan LN, Junqueira LAP. Construindo o "pacto de gestão" do SUS: da descentralização tutelada à gestão em rede. Rev C S Col 2007; 123(4):893-902.

11. Pinto ICM . Ascensão e queda de uma questão na agenda governamental: o caso das organizações sociais da saúde na Bahia [tese]. Salvado (Ba): Universidade Federal da Bahia; 2004.
12. Bresser-Pereira LC. Organizações sociais ou fundações estatais? A Tarde 2007 Out 8; p.11.

13. Brasil. M inistério do Planejamento, Orçamento e Gestão. Secretaria de Gestão Projeto Fundação Estatal: principais aspectos In: Anexo I Quadros Comparativos das Formas Jurídico-Institucionais.Quadro I. Brasília: Ministério do Planejamento; 2007. p.48-51.

14. Secretaria da Saúde do Estado da Bahia. Fundação Estatal Saúde da Família: proposta para debate. 3o versão; setembro de 2007. 64p.

15. Paim JS. Desafios para a saúde coletiva no século XXI. Salvador: EDUFBA; 2006.

16. Paim JS. Reforma Sanitária Brasileira: contribuição para a compreensão e crítica [tese]. Salvador (Ba): Universidade Federal da Bahia; 2007.

17. Centro Brasileiro de Estudos de Saúde. CEBES condena o loteamento político de cargos na saúde. 12 Junho de 2007. No prelo 2007.

18. Paim JS. Saúde Política e Reforma Sanitária. Salvador: CEPS-ISC; 2002.

19. Brasil. Ministério da Saúde. Medida Provisória no 33, 19 de fevereiro de 2002. Dispõe sobre os Sistemas Nacionais de Epidemiologia, de Saúde Ambiental e de Saúde Indígena, cria a Agência Federal de Prevenção e Controle de Doenças - APEC, e dá outras providências. Diário Oficial da União 2002; fev. [acessado 2007 outubro 10]. Disponível em: http://www.ipef.br/legislacao/bdlegislacao/arquivos/11917.rtf

20. Associação Brasileira de Pós-Graduação em Saúde Coletiva. Outra emenda pior que o soneto. APECnovas ameaças ao processo de descentralização da saúde. Boletim Abrasco 2002; 84:2-3.

Artigo apresentado em 27/09/2007

Aprovado em 11/10/2007

Versão final apresentada em 13/10/2007 
